\title{
Modeling of kinetics of drying process of polycaproamide granules considering its sorption properties
}

\section{Kosheleva M.K..$^{\text {a }}$; Dornyak O.R. ${ }^{\text {b; Maklusova M.S. }}{ }^{\text {a }}$}

${ }^{\text {a }}$ Russian state University after A. N. Kosygin (Technology. Design. Art), Moscow, Russia.

${ }^{\mathrm{b}}$ Voronezh State University of Forestry and Technologies after F.G. Morozov, Voronezh, Russia.

*E-mail of the corresponding author: oxtpaxt@yandex.ru

\begin{abstract}
The results of experimental and theoretical research of heat and mass transfer in polycaproamide granules during convective drying are presented.
\end{abstract}

Keywords: convective drying, mathematical modeling, polycaproamide. 


\section{Introduction}

Drying process of polycaproamide granules is one of the stages of technological chain during production of polyamide fiber caprone. Rather high level of dehydration of granules during drying process should be provide to obtain high quality fiber. Average final moisture content of the material should be not more than $0.1 \%$. We know that at low values of moisture content drying process of polycaproamide is sharply slows down and the distribution of moisture content is substantially nonuniform. In this case calculation of kinetics of granules dehydration should be provide using local coefficient values of mass transfer (diffusion of moisture). Results of calculations which illustrate features of heat and mass transfer processes during convective drying of cylindrical granules are presented. Two local parameters of mass transfer are using for calculation - coefficient of moisture diffusion in polycaproamide (in the form of a liquid) $a_{\mathrm{m}}$ and criteria of phase transfer $\varepsilon$. These parametres are depends on material moisture content and temperature in given point of material at certain point in time.

\section{Materials and Methods}

The object of drying is polycaproamide. Average degree of polymerization is 130-200, average molecular weight is $15000-23000$. The structure of samples was research by three independent methods. Method of mercury porosimetry, electron microscopy and sorption method were used.

The predominant pore radius is $1000 \AA$. Such pores are filled only at direct contact with liquid phase but not during sortion process and its presence in polycaproamide associated probably with mechanical impact during preparation of a substance but not with supramolecular structures. Photos of fracture of polycaproamide crumb obtained using an electron microscope confirm the presence of large pores in the material.

The specific volume of pores is $0.022 \mathrm{~cm}^{3} / \mathrm{g}$. Isotherm of sorption of moisture vapor by polycaproamide was obtain using vacuum sorption installation with weights of Mac-BenBakr. Maximum hygroscopic humidity at $22^{\circ} \mathrm{C}$ is about $8 \%$. The existence of a loop of sorption hysteresis the appearance of which indirectly indicates partial swelling of polycaproamide in water is established.

Drying kinetics curves for samples of polycaproamide received in convective dryer equipped with devices for monitoring and controlling the parameters of the drying agent The radius of the granule was $R_{g r}=1.375 \cdot 10^{-3} \mathrm{~m}$, length $-L_{g r}=4 \cdot 10^{-2} \mathrm{~m}$. The relative humidity of the environment was maintained equal to $\varphi_{\mathrm{c}} \sim 3 \%$. The speed of drying agent was $25 \mathrm{~m} / \mathrm{s}$. Kinetic curves at different temperatures in the range from 90 to $150^{\circ} \mathrm{C}$ are rpesented on Fig. 
1. The set air temperature was maintained with accuracy $0,1^{\circ} \mathrm{C}$. The weighing accuracy was $10^{-6} \mathrm{~kg} / \mathrm{m}^{3}$.

Character of experimental kinetics curves allow to draw a conclusion about essential nonlinearity of effective coeficient moisture conductivity in the granule of polycaproamide which is associated with the specific nature of phase transitions in macromolecular systems. The intensity of vaporization here depends not only on the amount of heat supplied but also on the rate of arrival of the volatile component to the evaporation surface (the outer surface of the granule and the interphase boundary of liquid-vapor in microcracks and pores). Diffusion transfer in polymer systems at low solvent contents is limiting for interfacial mass transfer [1].

\section{Mathematical model}

Nonstationary nonlinear axisymmetric 2D model similar [2] which generalizes the wellknown mathematical model of the diffusion-filtration heat and moisture transfer of A.V. Lykov [3] using for description of heat and mass transfer processes during drying. It is constructed as the limiting case of models based on the mechanics of multiphase systems [4-5]. The mathematical model includes transfer equations averaged over the microvolume of the material:

- liquid phase transfer equation

$$
\frac{\partial \mathrm{u}}{\partial \mathrm{t}}=\frac{1}{\mathrm{r}} \frac{\partial}{\partial \mathrm{r}}\left[\mathrm{ra}_{\mathrm{m}}(\mathrm{u}, \mathrm{T}) \frac{\partial \mathrm{u}}{\partial \mathrm{r}}\right]+\frac{\partial}{\partial \mathrm{z}}\left[\mathrm{a}_{\mathrm{m}}(\mathrm{u}, \mathrm{T}) \frac{\partial \mathrm{u}}{\partial \mathrm{z}}\right]-\frac{\mathrm{s}_{12} \mathrm{j}}{\alpha_{3} \rho_{3}^{0}}
$$

- heat transfer equation

$$
\begin{aligned}
& \mathrm{c} \rho \frac{\partial \mathrm{T}}{\partial \mathrm{t}}=\frac{1}{\mathrm{r}} \frac{\partial}{\partial \mathrm{r}}\left[\mathrm{r} \lambda(\mathrm{u}, \mathrm{T}) \frac{\partial \mathrm{T}}{\partial \mathrm{r}}\right]+\frac{\partial}{\partial \mathrm{z}}\left[\lambda(\mathrm{u}, \mathrm{T}) \frac{\partial \mathrm{T}}{\partial \mathrm{z}}\right]-\mathrm{L}_{12} \varepsilon \rho \frac{\partial \mathrm{u}}{\partial \mathrm{t}} ; \\
& \lambda=\alpha_{1} \lambda_{1}+\alpha_{2} \lambda_{2}+\alpha_{3} \lambda_{3} ; \mathrm{c} \rho=\alpha_{1} \mathrm{c}_{\mathrm{p} 1} \rho_{1}+\alpha_{2} \mathrm{c}_{\mathrm{p} 2} \rho_{2}+\alpha_{3} \mathrm{c}_{\mathrm{p} 3} \rho_{3} ;
\end{aligned}
$$

- equation for vapor-gas phase pressure

$$
\begin{aligned}
& \mathrm{c} \rho \frac{\partial \mathrm{p}_{1}}{\partial \mathrm{t}}=\mathrm{p}_{1} \frac{\mathrm{K}_{13}}{\mu_{1}}\left[\frac{1}{\mathrm{r}} \frac{\partial}{\partial \mathrm{r}}\left(\mathrm{r} \frac{\partial \mathrm{p}_{1}}{\partial \mathrm{r}}\right)+\frac{\partial^{2} \mathrm{p}_{1}}{\partial \mathrm{z}^{2}}\right]+\frac{\mathrm{p}_{1}}{\mathrm{c} \rho \mathrm{T}} \frac{\partial \mathrm{T}}{\partial \mathrm{t}}+\frac{\mathrm{p}_{1} \mathrm{~L}_{12} \varepsilon}{\mathrm{cT}} \frac{\partial \mathrm{u}}{\partial \mathrm{t}}+ \\
& +\frac{\mathrm{p}_{1}}{\mathrm{~B}_{1}} \frac{\partial \mathrm{B}_{1}}{\partial \mathrm{t}}-\frac{\mathrm{p}_{1}}{\alpha_{1}} \frac{\partial \alpha_{1}}{\partial \mathrm{t}}+\frac{\mathrm{s}_{12} \mathrm{jTB}_{1}}{\alpha_{1}}-\frac{\mathrm{p}_{1} \mathrm{~L}_{12} \varepsilon}{\mathrm{cT}} \cdot \frac{\mathrm{s}_{12} \mathrm{j}}{\alpha_{3} \rho_{3}} ;
\end{aligned}
$$

- equation for the concentration of the vapor component. 


$$
\begin{aligned}
& \frac{\partial\left(\alpha_{1} \rho_{1}(1-\chi)\right)}{\partial \mathrm{t}}=\frac{1}{\mathrm{r}} \frac{\partial}{\partial \mathrm{r}}\left[\mathrm{r}\left(\alpha_{1} \rho_{1}(1-\chi)\right)\left(\mathrm{v}_{1}^{\mathrm{r}}+\mathrm{w}_{1 \mathrm{~g}}^{\mathrm{r}}\right)\right]+ \\
& \left.+\frac{\partial}{\partial \mathrm{z}}\left[\alpha_{1} \rho_{1}(1-\chi)\right)\left(\mathrm{v}_{1}^{\mathrm{z}}+\mathrm{w}_{1 \mathrm{~g}}^{\mathrm{z}}\right)\right]=0 ; \chi=\frac{\rho_{1 \mathrm{v}}}{\rho_{1}} ; 1-\chi=\frac{\rho_{1 \mathrm{~g}}}{\rho_{1}} .
\end{aligned}
$$

Where: $\mathrm{a}_{\mathrm{m}}$ - water diffusion coefficient, $\mathrm{m}^{2} / \mathrm{s}$; B - individual gas constant, $\mathrm{J} /(\mathrm{kg} \cdot \mathrm{K})$; c thermal capacity, $\mathrm{J} /(\mathrm{kg} \cdot \mathrm{K}) ; \mathrm{j}$ - rate of evaporation, $\mathrm{kg} /\left(\mathrm{m}^{2} \cdot \mathrm{s}\right) ; \mathrm{K}_{\mathrm{ij}}$ - coefficient of i-phase penetrability in $\mathrm{j}$ - phase $\mathrm{m}^{2} ; \mathrm{L}_{12}$ - latent heat of evaporating water, $\mathrm{J} / \mathrm{kg} ; \mathrm{t}$ - time, $\mathrm{s} ; \mathrm{p}$ pressure, $\mathrm{Pa} ; \mathrm{T}$ - temperature, $\mathrm{K} ; \mathrm{r}$ - radial coordinate, $\mathrm{m}$; $\mathrm{R}$ - universal gas constant, $\mathrm{J} /(\mathrm{mol} \cdot \mathrm{K}) ; \mathrm{s}_{12}$ - specific surface area of the section of phases, $\mathrm{m}^{-1} ; \mathrm{u}$ - moisture content, $\mathrm{kg} /$ $\mathrm{kg} ; \mathrm{v}$ - velocity, $\mathrm{m} / \mathrm{s} ; \mathrm{w}$ - diffusive velocity, $\mathrm{m} / \mathrm{s} ; \mathrm{z}$ - axial coordinate, $\mathrm{m} ; \alpha$ - volumetric content, $\mathrm{m}^{3} / \mathrm{m}^{3} ; \varepsilon$ - criterion of phase transitions; $\varphi$ - relative humidity; $\lambda$ - thermal conductivity, $\mathrm{W} /\left(\mathrm{m}^{2} \cdot \mathrm{K}\right) ; \rho$ - density, $\mathrm{kg} / \mathrm{m}^{3} ; \chi$ - concentration of steam in a gas mixture, $\mathrm{kg} /$ kg. Subscripts: 1 - gas vapour mixture; 2 - fluid phase; 3 - solid phase; g - gas; $v$ - vapor; 0 - initial state. Superscripts: $r, \mathrm{z}$ - components of vectors.

The transfer equations (1-4) are supplemented by the equation of the sorption polytherm, the equations of state for the vapor and gas components, the Fick diffusion law, the Darcy filtration law, the Dalton law for calculating the intensity of phase transitions, the Antoine formula for determining the saturated vapor pressure at a defined temperature:

$$
\begin{aligned}
& \mathrm{u}=\mathrm{f}(\mathrm{T}, \varphi) ; p_{1}=\rho_{1} \mathrm{~TB}_{1} ; \mathrm{p}_{1 \mathrm{~g}}=\rho_{1 \mathrm{~g}} \mathrm{~TB}_{1 \mathrm{~g}} ; \mathrm{p}_{1 \mathrm{v}}=\rho_{1 \mathrm{v}} \mathrm{TB}_{1 \mathrm{v}} ; \rho_{1}=\rho_{1 \mathrm{v}}+\rho_{1 \mathrm{~g}} ; \\
& \mathrm{B}_{1}=\mathrm{B}_{1 \mathrm{v}}+(1-\chi) \mathrm{B}_{1 \mathrm{~g}} ; \mathrm{w}_{1 \mathrm{~g}}^{\mathrm{r}}=\frac{\rho_{1}}{\rho_{1 \mathrm{~g}}} \mathrm{D} \frac{\partial \chi}{\partial \mathrm{r}} ; \mathrm{w}_{1 \mathrm{~g}}^{\mathrm{z}}=\frac{\rho_{1}}{\rho_{1 \mathrm{~g}}} \mathrm{D} \frac{\partial \chi}{\partial \mathrm{z}} ; \mathrm{v}_{1}^{\mathrm{r}}=-\frac{\mathrm{K}_{13}}{\mu_{1}} \frac{\partial \mathrm{p}_{1}}{\partial \mathrm{r}} ; \\
& \mathrm{v}_{1}^{\mathrm{z}}=-\frac{\mathrm{K}_{13}}{\mu_{1}} \frac{\partial \mathrm{p}_{1}}{\partial \mathrm{z}} ; \mathrm{j}=\kappa_{2} \frac{\mathrm{p}_{\mathrm{sat}}(\mathrm{T})-\mathrm{p}_{1 \mathrm{v}}(\mathrm{T})}{\mathrm{p}_{\mathrm{atm}}} ; \mathrm{p}_{\mathrm{sat}}=\exp \left(\mathrm{A}_{\mathrm{s}}-\frac{\mathrm{B}_{\mathrm{s}}}{\mathrm{T}+\mathrm{C}_{\mathrm{s}}}\right) ;
\end{aligned}
$$

where: D - diffusion coefficient $\mathrm{m}^{2} / \mathrm{s} ; \mu$ - dynamic viscosity, Pa's; $\bar{v}$ - fluid molar volume, $\mathrm{m}^{3} / \mathrm{mol} ; \mathrm{A}_{\mathrm{s}}, \mathrm{B}_{\mathrm{s}}, \mathrm{C}_{\mathrm{s}}$ - empirical coefficients. Subscripts: atm - atmospheric; sat - saturation. The initial and boundary conditions have the form:

$$
\begin{aligned}
& \mathrm{T}(0, \mathrm{r}, \mathrm{z})=\mathrm{T}_{0} ; \mathrm{u}(0, \mathrm{r}, \mathrm{z})=\mathrm{u}_{0} ; \mathrm{p}_{1}(0, \mathrm{r}, \mathrm{z})=\mathrm{p}_{10} ; \chi(0, \mathrm{r}, \mathrm{z})=\chi_{0} ; \\
& -\left.\lambda \frac{\partial \mathrm{T}}{\partial \mathrm{n}}\right|_{\Gamma}=\alpha^{h}\left(\left.\mathrm{~T}\right|_{\Gamma}-\mathrm{T}_{\mathrm{c}}\right) ;\left.\mathrm{u}\right|_{\Gamma}=\mathrm{u}_{\mathrm{eq}} ; \chi_{\Gamma}=\chi_{\mathrm{c}} ;\left.\mathrm{p}_{1}\right|_{\Gamma}=\mathrm{p}_{\mathrm{c}} .
\end{aligned}
$$


Subscripts: eq - equilibrium; 0 - initial state; c - surrounding medium; $\Gamma$ - external boundary of a granule; $\mathrm{n}$ - normal. Parameter $\alpha^{\mathrm{h}}$ - coefficient of heat transfer, W/(m·K).

Important elements of the model are the original computational formulas for calculating the time-varying local diffusion coefficients of liquid $a_{\mathrm{m}}$ and the values of the phase transition criterion $\varepsilon$. These formulas were obtained by analyzing a more general mathematical model of heat and mass transport of transport constructed on the basis of the mechanics of multiphase systems [4-5]:

$$
\mathrm{a}_{\mathrm{m}}=-\frac{\mathrm{K}_{23}}{\mu_{2}} \frac{\mathrm{RTu}}{\bar{v}} \frac{1}{\varphi} \frac{\partial \varphi}{\partial \mathrm{u}} ; \varepsilon=\frac{\mathrm{C}_{\mathrm{v} 1}}{\mathrm{~L}_{12}} \frac{\mathrm{T}-\mathrm{T}_{\mathrm{sat}}}{1+\mathrm{u}} .
$$

The nonstationary nonlinear mathematical model (1-8) has been researched numerically. The equations are solved by an implicit method of finite differences using the control volume approach as described by [6].

\section{Results of experiments and numerical analysis}

Calculations were carried out at the values of the thermophysical parameters of water, water vapor, air according to [7]. For other parameters, the values are: $\rho_{3}=1150$; $\mathrm{K}_{13}=1.0 \cdot 10^{-16} \mathrm{~m}^{2} ; \mathrm{K}_{23}=1.5 \cdot 10^{-23} \mathrm{~m}^{2} ; \quad \kappa_{2}=1.7 \cdot 10^{-12} \mathrm{~kg} /\left(\mathrm{m}^{2} \cdot \mathrm{s}\right) ; \mathrm{s}_{12}=6.6 \cdot 10^{6} \mathrm{~m}^{-1} ; \lambda_{3}=0.25$ $\mathrm{W} /\left(\mathrm{m}^{2} \cdot \mathrm{K}\right) ; \mathrm{c}_{\mathrm{p} 3}=2100 \mathrm{~J} /(\mathrm{kg} \cdot \mathrm{K})$. The heat transfer coefficient $\alpha^{\mathrm{h}}$ was determined taking into account the drying agent's speed according to known empirical relationships. The polytherm of sorption of polycaproamide was obtained on the basis of experimental data:

$$
\mathrm{u}=\mathrm{u}_{\max }(\mathrm{T}) \varphi^{a_{0} k^{\varphi}} ; \mathrm{u}_{\max }(\mathrm{T})=\mathrm{u}\left(\mathrm{T}_{0}\right)-\alpha_{\mathrm{T}}\left(\mathrm{T}-\mathrm{T}_{0}\right) .
$$

The values of the parameters of the sorption polytherm are determined as follows: $\mathrm{a}_{0}=0.9567 ; \mathrm{k}=4.796 ; \mathrm{T}_{0}=295 \mathrm{~K} ; \mathrm{u}\left(\mathrm{T}_{0}\right)=0.08891 ; \alpha_{\mathrm{T}}=0.0002517 \mathrm{~K}^{-1}$.

The results of numerical calculations of drying kinetics of the polycaproamide granule satisfactorily coincide with the experimental curves of high-temperature drying (Fig. 1). By increasing the temperature of the air in the drying chamber, the duration of the process of dehydrating granules of polycaproamide can be significantly reduced. The drying of the granules at the temperature of the drying agent $T_{c}=423 \mathrm{~K}$ is approximately 4 times faster than at $\mathrm{T}_{\mathrm{c}}=383 \mathrm{~K}$. The influence of the ratio $R_{g r} / L_{g r}$ on the dewatering intensity of the granule is shown in Fig. 2. It should be noted that the main contribution to slowing down the drying process with increasing $R_{g r} / L_{g r}$ is not the shape of the granule (tablet or elongated cylinder), but its volume, which also increases. 


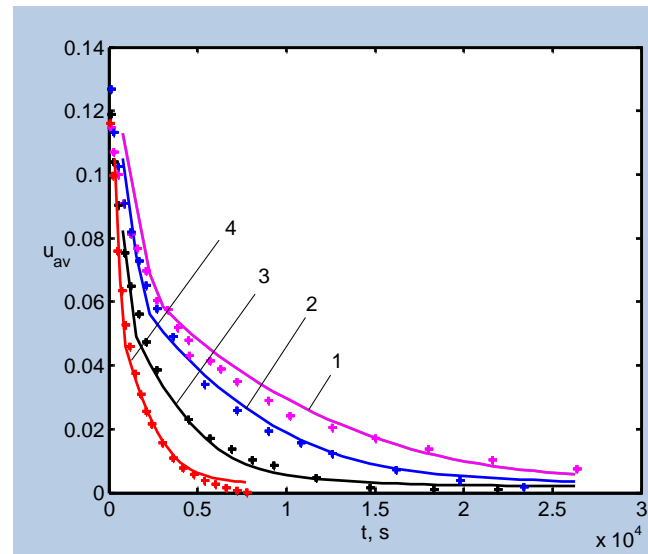

Fig. 1. The change in time with the average volume of moisture content of the polycaproamide granule with $R_{g r}=1.375 \cdot 10^{-3}$ $\mathrm{m}, \mathrm{L} g r=0.04 \mathrm{~m}$ at $\varphi_{c}=0.03$ for $\mathrm{T}_{c}=373 \mathrm{~K}-1$, $383-2,403-3,423-4$.

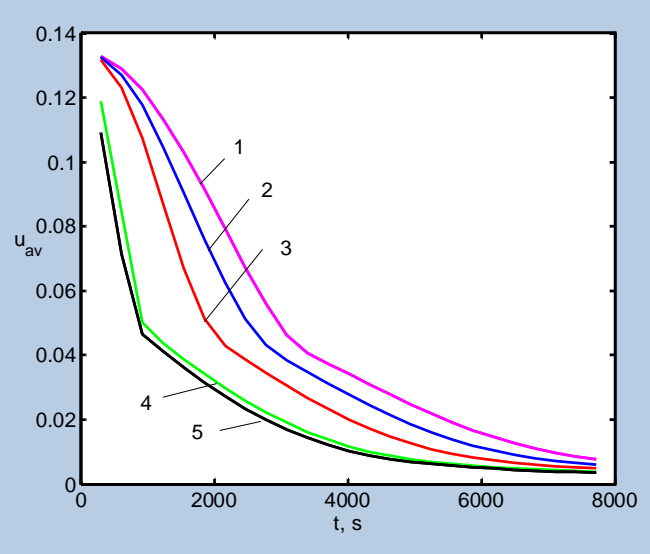

Fig. 2. The change in time with the average volume of moisture content of the polycaproamide granule at $T_{c}=423 \mathrm{~K}, \varphi_{c}=0.03$, $L_{g r}=0.04 m$ for $R g r / L_{g r}=5-1,1-2,0.5-3,0.1$ $-4,0.005-5$.

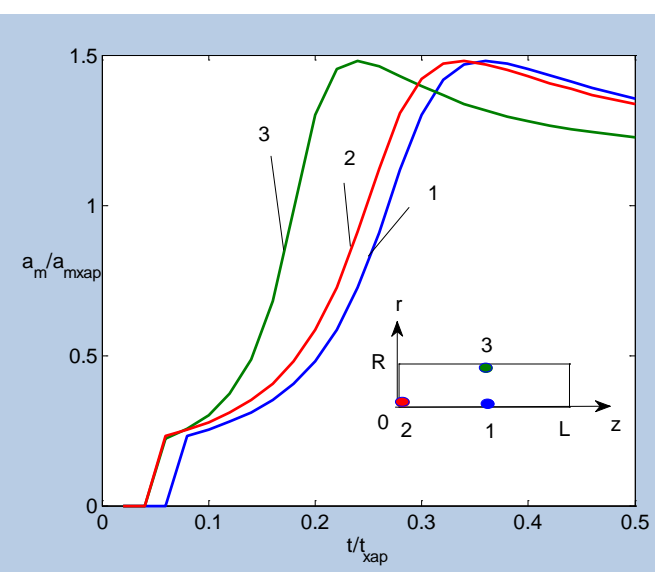

a)

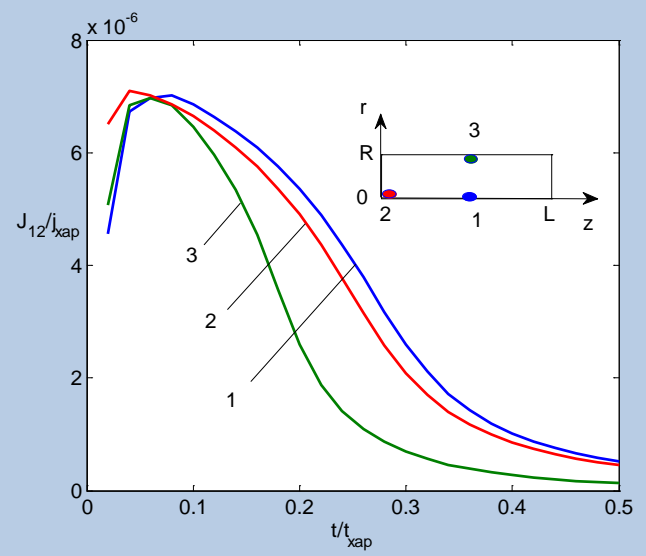

b)

Fig. 3. The change with time of the local values of the diffusion coefficient (a) and the intensity of vaporization (b) in the cross section of the polycaproamide at $T_{c}=423 \mathrm{~K}, \varphi_{c}=0.03 \%$ for $\mathrm{R}_{\mathrm{gr}} / \mathrm{Lgr}=0.1$,

$$
t_{x a p}=15456 \mathrm{~s}, a_{m \text { xap }}=1.63 \cdot 10^{-11} \mathrm{~m}^{2} / \mathrm{s}, j_{x a p}=3.06 \cdot 10^{-6} \mathrm{~kg} /\left(\mathrm{m}^{2} \cdot \mathrm{s}\right) \text {. }
$$

The moisture transfer in this process is carried out as a transfer of the liquid phase due to the gradient of the disjoining pressure in the boundary layers of water, if the moisture content of the material is below the maximum hygroscopic humidity, and also as the transfer of the vapor component, the production of which occurs throughout the volume of 
the granule. Fig. 3 illustrates how the contribution of different moisture transfer mechanisms at individual points of the cross section of the granule varies with time. The motion of the liquid phase, characterized by the value $a_{m}>0$, begins after the stage of material heating and intensive removal of moisture in the form of vapor. After a decrease in the value of $u$ below the maximum hygroscopic moisture content, a flow of liquid from the region with a higher saturation to a region of lower saturation begins at this temperature, with the diffusion coefficient $\mathrm{a}_{\mathrm{m}}$ increasing, reaching a maximum (Fig. 3a). The intensity of vaporization decreases (Fig.3b), which is associated with a decrease in saturated vapor pressure above the interphase surface and a decrease in its activity.

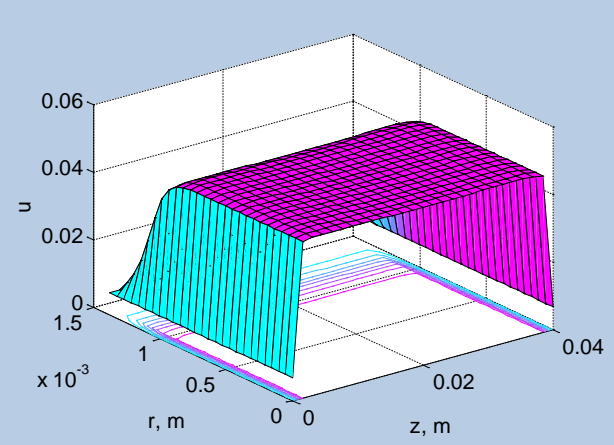

a)

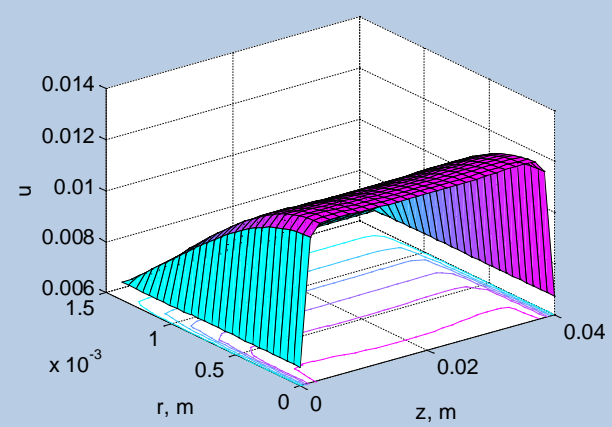

c)

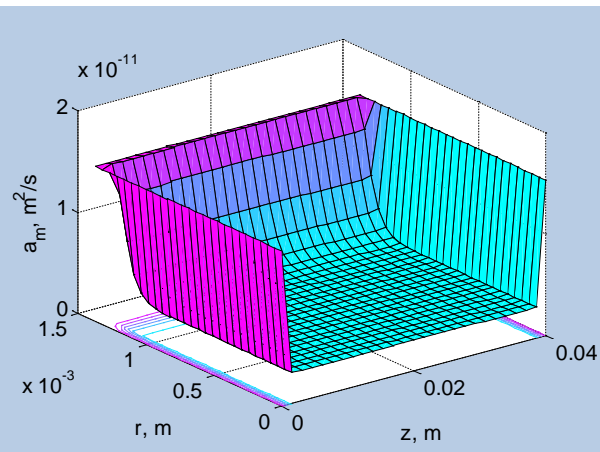

b)

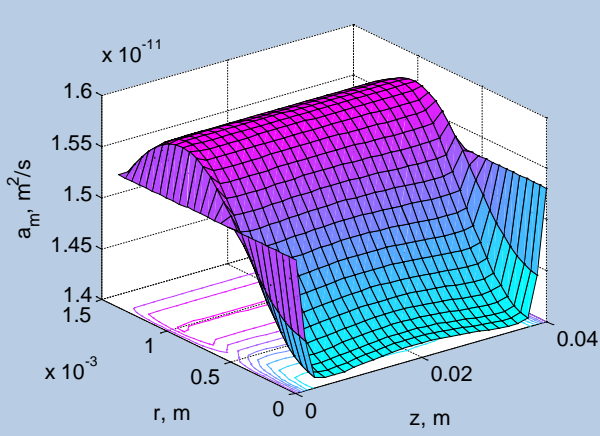

d)

Fig. 4. The distribution in the plane r-z moisture content (a,c) and local diffusion coefficient of liquid phase (b,d) at the instants $t=13138 s-(a, b), 19722-(c, d)$ during drying the granules with $R_{g r}=1.375 \cdot 10^{-3} \mathrm{~m}, L_{g r}=0.04 \mathrm{~m}$ at $T_{c}=383 \mathrm{~K}, \varphi_{c}=0.15, T_{0}=295 \mathrm{~K}, u_{0}=0.013$.

The distribution of the water diffusion coefficient over the granule cross-section and the corresponding moisture content distribution during drying are shown in Fig. 4 for different 
instants of time. In the early stages of dehydration in the central zone of the granule, the moisture content exceeds the maximum hygroscopic humidity. Mass transfer occurs here due to evaporation, the coefficient of diffusion transfer of water is practically zero (Fig. 4a). Over time, this area is reduced (Fig. 4c), and at the end of the process it disappears. The distribution of the water diffusion coefficient across the cross-section of the granule $a_{m}$ transforms with time (Fig. 4b, d) and gradually equalizes at low moisture content.

\section{Conclusions}

Comparison of the results of mathematical modeling of heat and mass transfer in the granule and data from the laboratory experiment on the kinetics of drying granules of polycaproamide showed good agreement between the calculated and experimental data. The constructed mathematical model allows to form energy-efficient regimes of granule polycaproamide drying.

\section{References}

[1] Levitsky, S.P.; Shulman, Z.P. Bubbles in Polymeric Liquids. Dynamics and HeatMass Transfer; Technomic Publishing Co.: Lancaster, 1995.

[2] Kosheleva, M.K.; Dornyak, O.R.; Apalkova, M.S. Mathematical modeling of heat and mass transfer during drying of granules carrier for nickel catalyst. In Proceedings of Second Nordic Baltic Drying Conference, Hamburg, Germany, June 7-9, 2017; 70.

[3] Luikov, A.V. Heat and Mass Transfer in Capillary-Porous Bodies; Pergamon Press: Oxford, 1966.

[4] Nigmatulin, R.I. Dynamics of multiphase media; Hemisphere: Washington, 1991.

[5] Whitaker, S. Simultaneous Heat, Mass and Momentum Transfers in Porous Media: A Theory of Drying. Advances of Heat Transfer 1977, 13, 119 - 203.

[6] Patankar, S. V. Numerical heat transfer and fluid flow; Hemisphere: Washington, 1980.

[7] Vargaftik, N.B. Handbook of thermophysical properties of gases and liquids; Science: Moscow, 1972. 